\title{
Kinetic study of carbon dioxide catalytic methanation over cobalt-nickel catalysts
}

Alla G. Dyachenko, Olena V. Ischenko, Snizhana V. Gaidai,

Tetiana M. Zakharova, Andrii V. Yatsymyrskyi, Vladyslav V. Lisnyak

Department of Chemistry, Taras Shevchenko National University of Kyiv, Volodymyrska Street, 64/13, Kyiv 01601, Ukraine

vladyslavlisnyak@yahoo.com, lisnyak@chem.univ.kiev.ua

Keywords: Sabatier process, bimetallic catalysts, catalytic methanation of $\mathrm{CO}_{2}$, kinetic patterns.

Based on the data of the thermoprogrammed desorption and using mass-spectroscopic analysis of desorbed products and on the kinetic patterns of the methanation process for cobalt-nickel catalysts, we suggested a mechanism for the reaction which passes through forming intermediate formyl compounds: $\mathrm{CHO}^{*}, \mathrm{HCOH}^{*}$, and $\mathrm{HCOOH}^{*}$. Because of the high stability of the carbon dioxide molecule, the step of adding the first hydrogen atom is the limiting step. Such a mechanism is in good agreement with the proposed kinetic equations.

\section{Introduction}

The electrolytic splitting water into hydrogen is one of the remarkable solutions at conversing surplus electricity into fuels [1]. The resulting gas reserves can be effectively stored for further use in fuel cells.

These fuel cells will generate electric energy at the highest point of seasonal consumption of electricity by customers [2]. In addition, the Sabatier process that can be shown by equation

$\mathrm{CO}_{2}+4 \mathrm{H}_{2}=\mathrm{CH}_{4}+2 \mathrm{H}_{2} \mathrm{O}$

is a more convenient and safe way to accumulate the energy by converting electrochemically generated hydrogen into methane [3].

Methane, the main component of synthetic natural gas, has several advantages over hydrogen, for example, higher volumetric energy content [4]. Using methane is lowering the risk of the gas leakage and explosion of gasoxygen mixtures. The undoubted plus is also that the infrastructure of the existing gas networks can be used for methane consumption.

Alternatively, the methane production can be done by a combined Sabatier reaction/water electrolysis process [5]. A mixture of gases $\mathrm{H}_{2}$, $\mathrm{CO}, \mathrm{CO}_{2}$ (syngas) obtained from alkaline water electrolysis using graphite electrodes $(1 \mathrm{~kW}$ prototype) was used instead of producing just oxygen and hydrogen as in the common alkaline electrolysis process. The syngas has been subjected to methanation over $\mathrm{Ni} / \mathrm{CaO}-\mathrm{Al}_{2} \mathrm{O}_{3}$ catalyst at 1 bar and different temperatures. 
In the reported installation [5], one can achieve a $\mathrm{CH}_{4}$ yield of $25.5 \%$ and $44.2 \% \mathrm{CO}_{2}$ conversion into $\mathrm{CH}_{4}$ at $96.5 \%$ selectivity towards $\mathrm{CH}_{4}$. In this way, one can produce methane fuel on-line in remote locations.

The complete $\mathrm{CO}_{2}$ methanation in hydrogen is an exothermic reaction. It has a negative enthalpy of $-164.7 \mathrm{~kJ}$ mole $^{-1}$. This methanation of $\mathrm{CO}_{2}$ is an eight-electron process with significant kinetic difficulties [6-8]. Therefore, an efficient catalyst is required to achieve high selectivity towards methane at acceptable reaction rates. In recent years, to develop thermostable catalysts with high activity at low temperatures, extensive researches have been conducted, as evidenced by the growing number of publications [9-11].

For industrial usage, cobalt and nickel catalysts have been extensively investigated because of their low cost and availability. However, the active $\mathrm{Ni}$ catalyst can be deactivated even at low temperatures because of the sintering of metal particles as a result of nickel carbonyls formation [12]. Many methods have been tested to increase the stability and activity of Ni-based catalysts, for example, by adding different catalytic systems or oxides, as well as changing types of carriers and methods of the catalyst preparation $[13,14]$.

Carbon dioxide is a source of carbon for not only methane but alcohols and other organic compounds synthesis. The catalytic reactions occur at low reaction temperature and not require additional energy. Among the wide range of combinations of transition metals, the particular interest arouses that of $\mathrm{Ni}$ and $\mathrm{Ni}-\mathrm{Co}$ having high selectivity towards methane [15, 16]. At this moment, there is no consensus on the mechanism for the reaction of hydrogenation of $\mathrm{CO}_{2}[17,18]$ and also remains unexplored a significant part of potentially effective combinations of the active phase, promoter, and carrier. Consequently, the search for new methanation catalysts and the study of the reaction mechanism remains the actual task.

In this work, to suggest the reaction mechanism, we considered the methanation kinetics and thermal desorption from the surface of Co-Ni catalysts.

\section{Experimental part}

\section{Material and methods}

The gases used at kinetic experiments are hydrogen taken from a hydrogen generator, carbon dioxide (99.8\%) and helium (99.995\%) taken from gas cylinders.

We studied high active $\mathrm{Co}_{80} \mathrm{Ni}_{20}$ and low active $\mathrm{C}_{35} \mathrm{Ni}_{65}$ catalysts. For them, the methane yield reaches $65 \%$ and $40 \%$ at $325{ }^{\circ} \mathrm{C}$. To prepare $\mathrm{Co}_{35} \mathrm{Ni}_{65}$ and $\mathrm{Co}_{80} \mathrm{Ni}_{20}$ catalysts, mixtures of pure metal powders of $\mathrm{Ni}$ and $\mathrm{Co}$ were taken in the nominal ratio of $35: 65$ and 80:20 mass\% Co:Ni. They were dissolved in 50 $\mathrm{ml}$ of concentrated $55 \mathrm{vol} . \% \mathrm{HNO}_{3}$ and refluxed using a sand bath for $30 \mathrm{~min}$. When both metals dissolved, the nitrate solution was cooled and 
then poured into $25 \mathrm{ml}$ of $18 \%(\mathrm{w} / \mathrm{v})$ $\mathrm{NH}_{4} \mathrm{OH}$. The prepared solution was adjusted to $\mathrm{pH} 7$ then stirred for $10 \mathrm{~min}$ and concentrated at $100{ }^{\circ} \mathrm{C}$ for $4 \mathrm{~h}$. Precipitated solids obtained by the evaporation was calcined at $350{ }^{\circ} \mathrm{C}$ for $4 \mathrm{~h}$ to yield a mixture of $\mathrm{NiO}$ and $\mathrm{CoO}$ powders. These oxide mixtures were reduced to $\mathrm{Co}-\mathrm{Ni}$ metal catalysts in a gas flow of $50 \mathrm{vol} \% \mathrm{H}_{2}$ rest $\mathrm{He}$ at $375^{\circ} \mathrm{C}$ for $4 \mathrm{~h}$, at atmospheric pressure.

Kinetic studies were conducted in a gradientless reactor at a pressure of 0.1 $\mathrm{MPa}$ and the constant concentration of selected reagent $\left(\mathrm{C}\left(\mathrm{CO}_{2}\right)\right.$ or $\left.C\left(\mathrm{H}_{2}\right)\right)$. This reactor was operated under a continuous flow of reagents mixture diluted by helium gas-carrier. At $C\left(\mathrm{CO}_{2}\right)=0.6 \times 10^{-3} \mathrm{~mol} / \mathrm{L}$, $C\left(\mathrm{H}_{2}\right)$ varied from $3 \times 10^{-3}$ to $3.2 \times 10^{-2}$ $\mathrm{mol} / \mathrm{L} ;$ at $C\left(\mathrm{H}_{2}\right)=8.17 \times 10^{-3} \mathrm{~mol} / \mathrm{L}$, $\left.C\left(\mathrm{CO}_{2}\right)\right)$ varied from $0.7 \times 10^{-3}$ to $3.0 \times 10^{-2}$ mol/L. The constant concentration of reagent was selected in such a way to maintain the conversion of $\mathrm{CO}_{2}$ below $20 \%$. A gas sample was taken from the reactor outlet to be analyzed.

The chromatographic analysis for $\mathrm{CO}_{2}$, $\mathrm{CO}$, and $\mathrm{CH}_{4}$ was performed with a thermal conductivity detector on a Shimadzu 2014 GC. A column packed with 5A molecular sieves was used for gas separation. Kinetic regularities of methanation were determined by measuring the rate of formation of $\mathrm{CH}_{4}$ and $\mathrm{CO}$ against the reactant concentration. The reaction rate $(r$, mol $\times \mathrm{s}^{-1} \mathrm{~m}^{-2}$ ) was calculated by the formula

$$
r=C U / g S
$$

where $C$ is the $\mathrm{CO}_{2}$ concentration at the outlet of the reactor, $\operatorname{mol} \times \mathrm{m}^{-3}, U$ is the volume rate of gas flow of $1.67 \times 10^{-6} \mathrm{~m}^{3} \times \mathrm{s}^{-1}$, $\mathrm{g}$ is the catalyst mass of $1 \mathrm{~g}$, and $S$ is the specific surface area of the catalyst in $\mathrm{m}^{2} \times \mathrm{g}^{-1}$.

The reaction temperature was selected for each sample in such a way to maintain the $\mathrm{CO}_{2}$ conversion below $20 \%$. The reaction orders with respect to reactants were calculated by the Van't Hoff method, at a fixed concentration of the selected component of the reaction mixture.

Thermodesorption studies after catalysis were performed by thermoprogrammed desorption mass spectrometry (TPD MS). The thermal analysis was carried out in the temperature range of $30-800{ }^{\circ} \mathrm{C}$, at a heating rate of $10{ }^{\circ} \mathrm{C} / \mathrm{min}[19]$.

\section{Results and discussion}

For $\mathrm{Co}_{35} \mathrm{Ni}_{65}$ catalyst, the reaction order of $\mathrm{CO}$ formation towards $\mathrm{H}_{2}$ showed an increase with reaction temperature (Figure 1a).

Thus, the reaction order is 0.09 at $225^{\circ} \mathrm{C}, 0.13$ at $240{ }^{\circ} \mathrm{C}$, and 0.52 at $255^{\circ} \mathrm{C}$. 

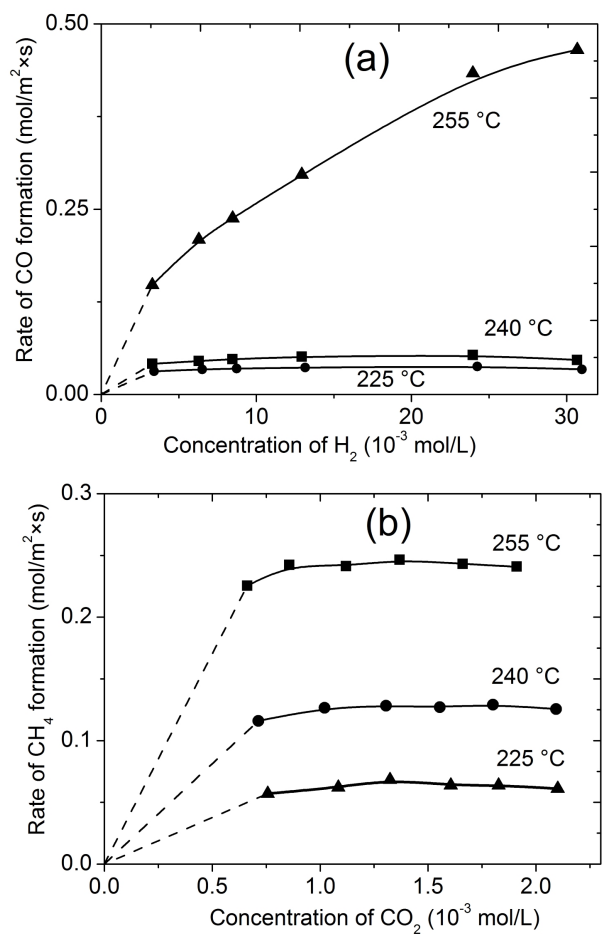

Figure 1. (a) $\mathrm{CO}$ and (b) $\mathrm{CH}_{4}$ formation rate against $\mathrm{H}_{2}$ concentration for $\mathrm{Co}_{35} \mathrm{Ni}_{65}$ catalyst.
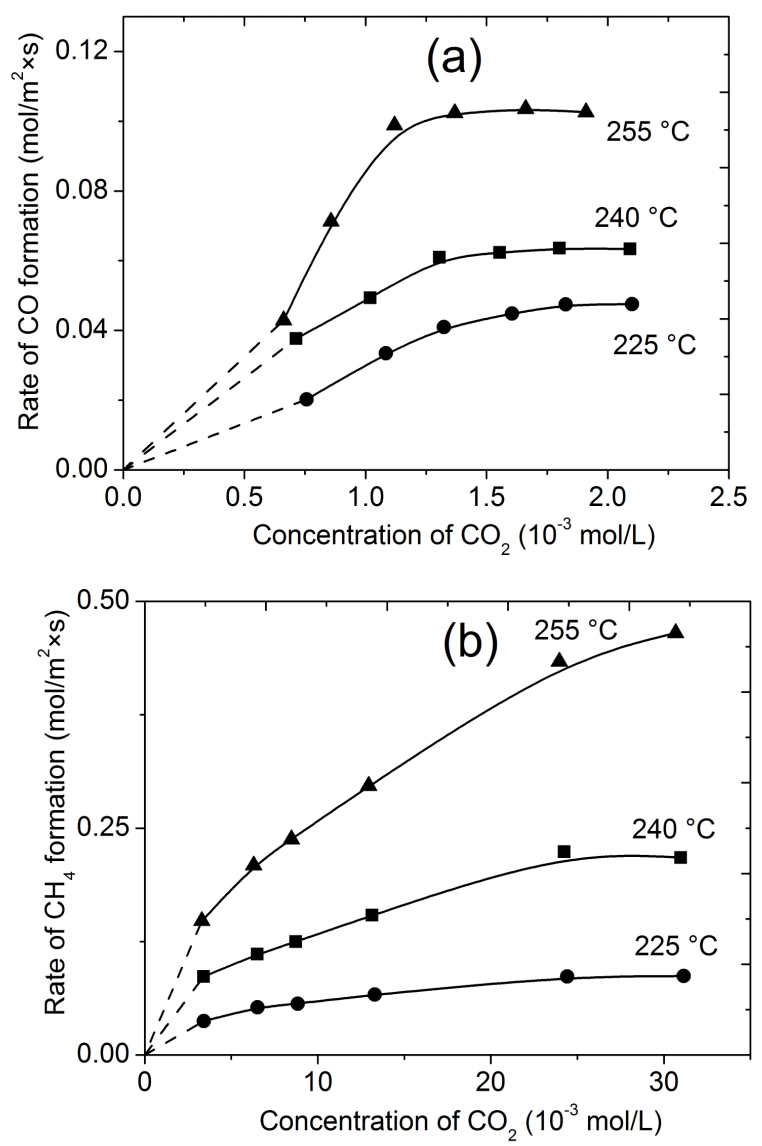

Figure 2. (a) $\mathrm{CO}$ and (b) $\mathrm{CH}_{4}$ formation rate against $\mathrm{CO}_{2}$ concentration for $\mathrm{Co}_{35} \mathrm{Ni}_{65}$ catalyst.
Figure 1b shows the reaction order of $\mathrm{CH}_{4}$ formation towards $\mathrm{H}_{2}$ is markedly increased with temperature, e.g., 0.39 at $225{ }^{\circ} \mathrm{C}, 0.45$ at $240{ }^{\circ} \mathrm{C}$, and 0.52 at $255^{\circ} \mathrm{C}$.

For this catalyst, the reaction order of $\mathrm{CO}$ formation towards $\mathrm{CO}_{2}$ shows a strong dependence on the $\mathrm{CO}_{2}$ concentration. The reaction order of $\mathrm{CO}$ formation towards $\mathrm{CO}_{2}$ is decreasing from 1.28 to 0.5 at $225{ }^{\circ} \mathrm{C}$, see Figure 2a.

We observed the same decrease from 0.79 to 0.0 at $240{ }^{\circ} \mathrm{C}$ and from 1.58 to 0.23 at $255^{\circ} \mathrm{C}$. The reaction order of $\mathrm{CH}_{4}$ formation towards $\mathrm{CO}_{2}$ showed the same zeroth order at 225,240 , and $255^{\circ} \mathrm{C}$ (Figure 2b).
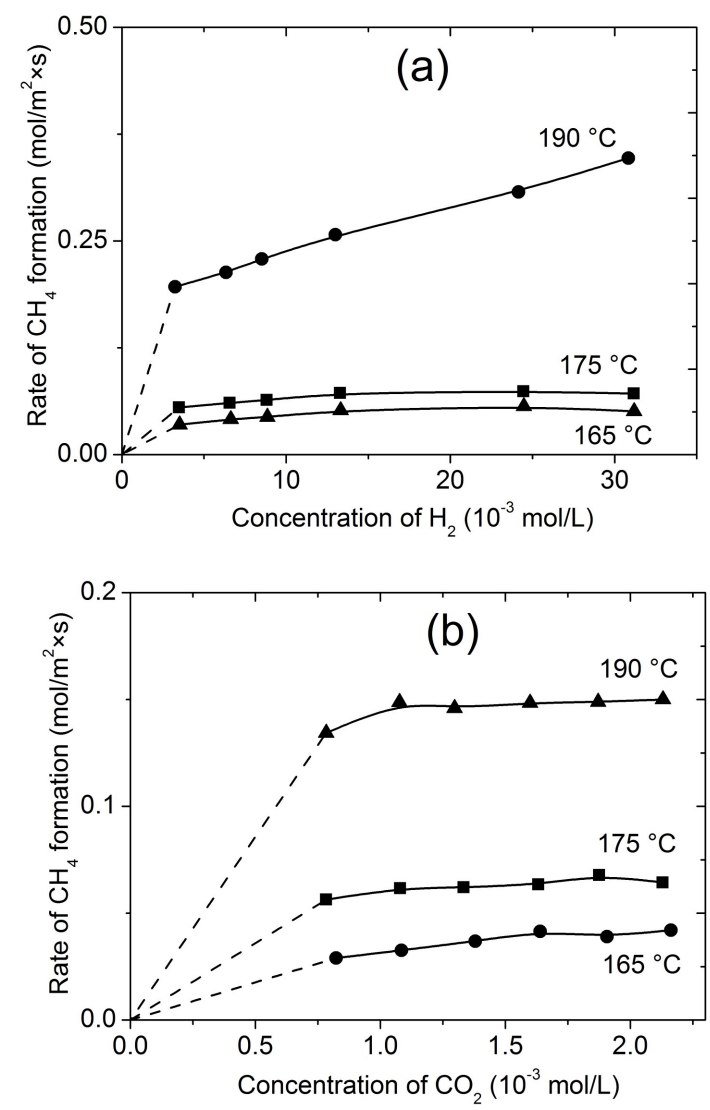

Figure 3. $\mathrm{CH}_{4}$ formation rate against (a) $\mathrm{H}_{2}$ and (b) $\mathrm{CO}_{2}$ concentrations for $\mathrm{Co}_{80} \mathrm{Ni}_{20}$ catalyst. 
For the most active $\mathrm{Co}_{80} \mathrm{Ni}_{20}$ catalyst, $\mathrm{CO}$ was not observed within the reaction products. The reaction order for $\mathrm{CH}_{4}$ formation with respect to $\mathrm{H}_{2}$ is 0.19 at $165^{\circ} \mathrm{C}, 0.13$ at $175^{\circ} \mathrm{C}$, and 0.25 at $190{ }^{\circ} \mathrm{C}$ (Figure 3a). The reaction order for $\mathrm{CH}_{4}$ formation with respect to $\mathrm{CO}_{2}$ is 0.22 at $165{ }^{\circ} \mathrm{C}, 0.12$ at $175{ }^{\circ} \mathrm{C}$ and 0.02 at $190{ }^{\circ} \mathrm{C}$ (Figure 3b).

Data from TPD MS analysis showed the presence on strongly and weakly bonded $\mathrm{HCO}^{*}$, $\mathrm{HCOH}^{*}$, and $\mathrm{HCOOH}^{*}$ intermediates of the gradual hydrogenation of $\mathrm{CO}_{2}$ molecule at the active catalyst site (Figure 4).
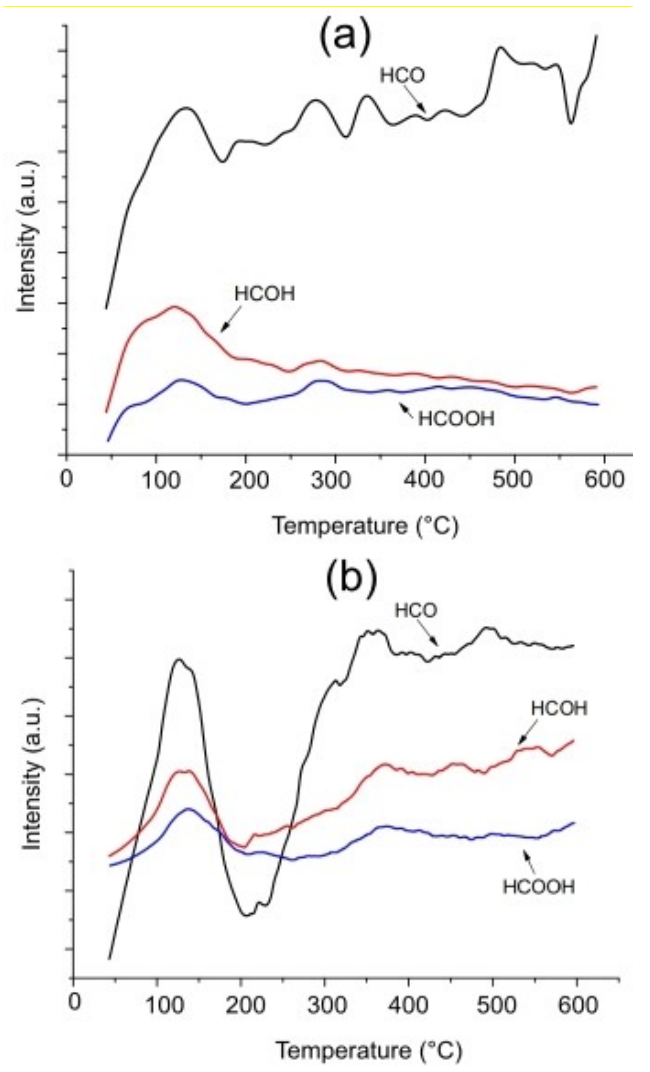

Figure 4. TPD MS profiles of $\mathrm{HCO}^{*}, \mathrm{HCOH}^{*}$, and $\mathrm{HCOOH}^{*}$ for (a) $\mathrm{Co}_{35} \mathrm{Ni}_{65}$ and (b) $\mathrm{Co}_{80} \mathrm{Ni}_{20}$ catalysts.

Based on the obtained results, the following kinetic description of the reaction on the $\mathrm{Co}-\mathrm{Ni}$ catalysts can be done, and the $\mathrm{CO}_{2}$ methanation reaction mechanism can be suggested. Here below $[\ldots]$ is the free adsorption site, $r$ is the rate reaction of $\mathrm{CH}_{4}$ formation from $\mathrm{CO}_{2}, \theta \varnothing$ is the fraction of free adsorption sites, $\theta_{\mathrm{H}}, \theta_{\mathrm{CO} 2}$, and $\theta_{\mathrm{HCO}_{2}}$ are fractions of the adsorption sites occupied by $\mathrm{H}, \mathrm{CO}_{2}$, and $\left[\mathrm{HCO}_{2}\right]$, respectively, $p\left(\mathrm{H}_{2}\right)$ and $p\left(\mathrm{CO}_{2}\right)$ are partial pressures of $\mathrm{H}_{2}$ and $\mathrm{CO}_{2}$.

$$
\mathrm{CO}_{2}+[] \stackrel{k_{1}}{\longrightarrow}\left[\mathrm{CO}_{2}\right]
$$

where $k_{1}$ is the $\mathrm{CO}_{2}$ adsorption constant.

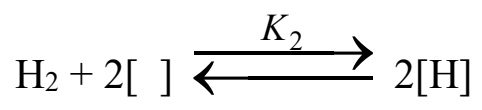

where $K_{2}$ is the equilibrium reaction constant.

$$
\left[\mathrm{CO}_{2}\right]+[\mathrm{H}] \stackrel{k_{3}}{\longrightarrow}\left[\mathrm{HCO}_{2}\right]
$$

$k_{3}$ is the $\mathrm{CO}_{2}$ methanation constant. This is a slow process since $\theta_{\mathrm{HCO}_{2}} \rightarrow 0$.

$$
\left[\mathrm{HCO}_{2}\right]+\mathrm{n}[\mathrm{H}] \stackrel{k_{4}}{\longrightarrow} \mathrm{P}
$$

where $\mathrm{P}$ means products, here is realized the fast process of $\left[\mathrm{H}_{2} \mathrm{COO}\right],\left[\mathrm{H}_{2} \mathrm{CO}\right], \ldots$, and $\mathrm{CH}_{4}$ formation. According to the literature [20], $\mathrm{CH}$, $\mathrm{CH}_{2}$, and $\mathrm{CH}_{3}$ are formed very quickly; therefore, they forming are not presented as separate stages of the mechanism.

From the aforementioned assumptions, we have

$$
\begin{aligned}
& \frac{d \theta_{\mathrm{CO}_{2}}}{d t}=0 \\
& k_{1} p_{\mathrm{CO}_{2}} \theta_{\varnothing}-k_{3} \theta_{\mathrm{CO}_{2}} \theta_{\mathrm{H}}=0 \\
& \theta_{\mathrm{CO}_{2}}=\frac{k_{1} p_{\mathrm{CO}_{2}} \theta_{\varnothing}}{k_{3} \theta_{\mathrm{H}}}
\end{aligned}
$$




$$
\begin{gathered}
K_{2}=\frac{\theta_{\mathrm{H}}^{2}}{p_{\mathrm{H}_{2}} \theta_{\varnothing}^{2}} \\
\theta_{\mathrm{H}}=\left(K_{2} p_{\mathrm{H}_{2}}\right)^{1 / 2} \theta_{\varnothing} \\
\theta_{\mathrm{CO}_{2}}=\frac{k_{1} p_{\mathrm{CO}_{2}}}{k_{3}\left(K_{2} p_{\mathrm{H}_{2}}\right)^{1 / 2}} \\
1=\theta_{\varnothing}+\theta_{\mathrm{H}}+\theta_{\mathrm{CO}_{2}} \\
\theta_{\varnothing} \theta_{\varnothing}\left(K_{2} p_{\mathrm{H}_{2}}\right)^{1 / 2}+\frac{k_{1} p_{\mathrm{CO}_{2}}}{k_{3}\left(K_{2} p_{\mathrm{H}_{2}}\right)^{1 / 2}}=1 \\
\theta_{\varnothing}=\frac{k_{1} p_{\mathrm{CO}_{2}}}{1+\left(K_{2} p_{\mathrm{H}_{2}}\right)^{1 / 2}} \\
r=k_{3} \theta_{\mathrm{CO}_{2}} \theta_{\mathrm{H}}=\frac{\left(k_{1} p_{\mathrm{CO}_{2}}\right)^{2}}{k_{1} p_{\mathrm{CO}_{2}}-\frac{k_{3}\left(K_{2} p_{\mathrm{H}_{2}}\right)^{1 / 2}}{1+\left(K_{2} p_{\mathrm{H}_{2}}\right)^{1 / 2}}}
\end{gathered}
$$

From these equations, the following relations can be derived for the reaction order of $\mathrm{CH}_{4}$ formation with respect to $\mathrm{CO}_{2}$

$$
p_{\mathrm{CO}_{2}}>p_{\mathrm{H}_{2}} \Rightarrow r=k_{1} p_{\mathrm{CO}_{2}}
$$

This means that the reaction order of $\mathrm{CH}_{4}$ formation with respect to $\mathrm{CO}_{2}$ is in the range from 0.0 to 1.0. For the reaction order of $\mathrm{CH}_{4}$ formation with respect to $\mathrm{H}_{2}$, we get

$$
p_{\mathrm{H}_{2}}>p_{\mathrm{CO}_{2}} \Rightarrow r=\frac{k_{1} p_{\mathrm{CO}_{2}}}{\sqrt{K_{2} p_{\mathrm{H}_{2}}}}
$$

That is, the reaction order of $\mathrm{CH}_{4}$ formation with respect to $\mathrm{H}_{2}$ is in the range from -0.5 to 0.5 , which does not contradict our experimental data.

\section{Conclusions}

Kinetic patterns of the methanation process for these catalysts showed a complex character. We proposed the mechanism which stages are based on data of kinetic measurements combined with TPD MS data. From TPD MS analysis, we found formyl intermediate compounds that are strongly and weakly bonded to the catalyst surface. We proposed the four-stage mechanism for the reaction considering the one atom hydrogenation of $\mathrm{CO}_{2}$ as the limiting step. Such a mechanism is in good agreement with the data given.

\section{References}

[1] Petipas F. Conception et conduite de systèmes d'électrolyse à haute température alimentés par des énergies renouvelables. Paris: MINES ParisTech; 2013, p. 180.

[2] De Saint Jean M, Baurens P, Bouallou C, Couturier K. Economic assessment of a power-tosubstitute-natural-gas process including high temperature steam electrolysis. Int $\mathrm{J}$ Hydrogen Energy 2015;40(20):6487-6500.

[3] Rönsch S, Schneider J, Matthischke S, and et.al. Review on methanation - From fundamentals to current projects. Fuel 2016;166:276-296.

[4] Sherif SA, Yogi Goswami D, (Lee) Stefanakos EK, Steinfeld A. Handbook of Hydrogen Energy. Boca Raton: CRC Press; 2014, p. 1058.

[5] Guerra L, Rossi S, Rodrigues J, Gomes J, Puna J, Santos MT. Methane production by a combined Sabatier reaction/water electrolysis process. J Environ Chem Eng 2018;6:671-676.

[6] Prieto G. Carbon dioxide hydrogenation into higher hydrocarbons and oxygenates: thermodynamic and kinetic bounds and progress with heterogeneous and 
homogeneous catalysis. ChemSusChem 2017;10(6):10561070 .

[7] Miguel CV, Soria MA, Mendes A, Madeira LM. Direct $\mathrm{CO}_{2}$ hydrogenation to methane or methanol from post-combustion exhaust streams-A thermodynamic study. J Natural Gas Sci Eng 2015;22:18.

[8] Swapnesh A, Srivastava VC, Mall ID. Comparative study on thermodynamic analysis of $\mathrm{CO}_{2}$ utilization reactions. Chem Eng Technol 2014;37(10):1765-1777.

[9] Meshkini Far R, Ischenko OV, Dyachenko AG. and et al. $\mathrm{CO}_{2}$ hydrogenation into $\mathrm{CH} 4$ over Ni-Fe catalysts Funct. Mater. Lett. 2018;11:1850057.

[10] Zhludenko M, Dyachenko A, Bieda O, and et.al. Structure and catalytic properties of $\mathrm{Co}-\mathrm{Fe}$ systems in the reaction of $\mathrm{CO}_{2}$ methanation. Acta Phys Polonica A 2018;133:1084-1087.

[11] $\mathrm{Su} \mathrm{X}, \mathrm{Xu}$ J, Liang B, and et.al. Catalytic carbon dioxide hydrogenation to methane: A review of recent studies. J Energy Chem 2016;25:553-565.

[12] Agnelli M, Kolb M, Mirodatos C. CO Hydrogenation on a Nickel Catalyst. J Catal 1994;148:921.

[13] Aziz MAA, Jalil AA, Triwahyono S, Ahmad A. $\mathrm{CO}_{2}$ methanation over heterogeneous catalysts: Recent progress and future prospects. Green Chem 2015;17:2647-2663.

$\begin{array}{cccc}{[14]} & \text { Kustov LM, } & \text { Tarasov AL. } \\ \text { Hydrogenation of carbon dioxide: a comparison of }\end{array}$

different types of active catalysts. Mendeleev Commun 2014:24:349-350.

[15] Alrafei B, Polaert I, Ledoux A and et al. Remarkably stable and efficient $\mathrm{Ni}$ and Ni-Co catalysts for $\mathrm{CO}_{2}$ methanation Catal Today 2019, in press. https://doi.org/10.1016/j.cattod.2019.03.026

[16] Martínez J, Hernández E, Alfaro S; and et al. High Selectivity and Stability of Nickel Catalysts for $\mathrm{CO}_{2}$ Methanation: Support Effects. Catalysts 2019;9:24.

[17] Miao B, Ma SSK, Wang X. et al. Catalysis mechanisms of $\mathrm{CO}_{2}$ and $\mathrm{CO}$ methanation. Catalysis Sci Technol 2016;6(12):4048-4058.

[18] Baraj E, Vagaský S, Hlinčík T and et al. Reaction mechanisms of carbon dioxide methanation. Chem Pap 2016;70:395-403.

[19] Ishchenko EV, Boldyreva NA, Tsapyuk GG, Yatsimirskii AV. State of carbon monoxide adsorbed on the surface of $\mathrm{Pd}, \mathrm{Pd}-\mathrm{Ag}$, and $\mathrm{Ag}$ catalysts deposited on $\mathrm{Al}_{2} \mathrm{O}_{3}$. Russ J Phys Chem 2000;74:S541-543.

[20] Kwak JH, Kovarik L, Szanyi J. Heterogeneous catalysis on atomically dispersed supported metals: $\mathrm{CO}_{2}$ Reduction on multifunctional $\mathrm{Pd}$ catalysts. ACS Catal. 2013;3:2094-2100. 